\title{
Endoluminal vacuum therapy for anastomotic insufficiency after gastrectomy
}

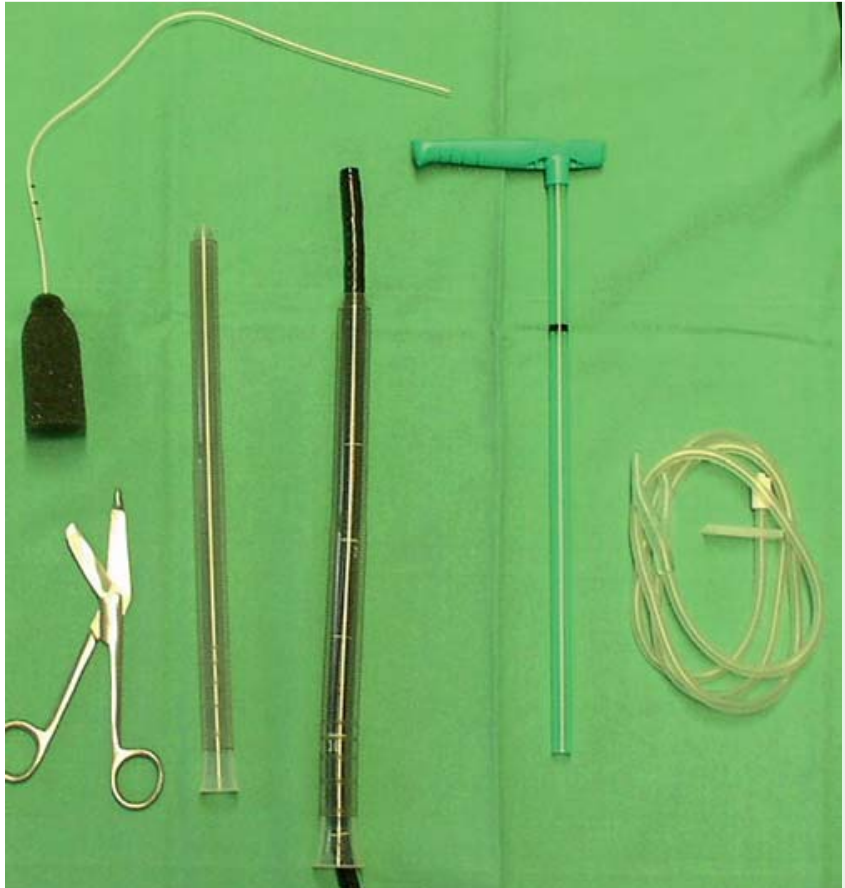

Fig. 1 The EndoSPONGE system: the sponge and drain.
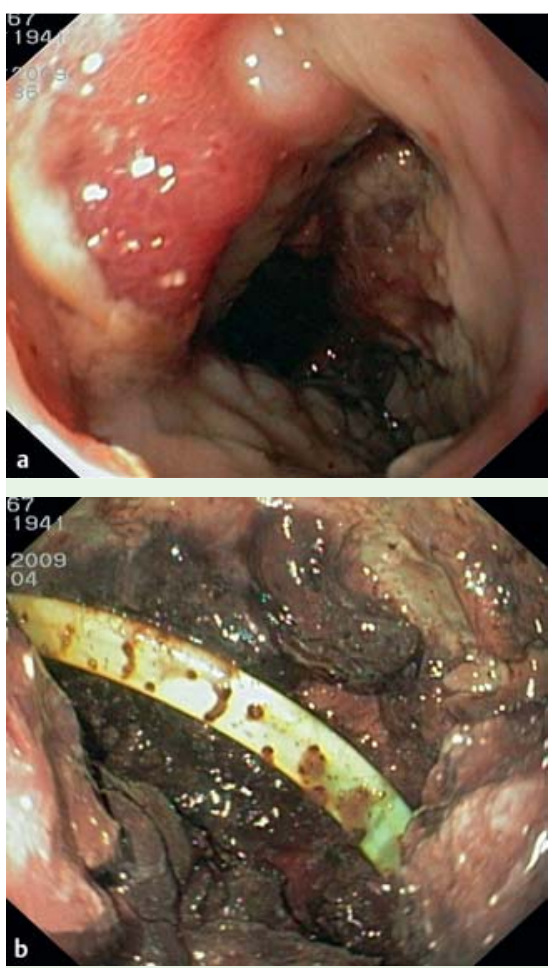

Fig. 3 Endoscopic views at the start of the treatment showing: a the anastomotic leak; and $\mathbf{b}$ the abdominal cavity, seen through the fistula.
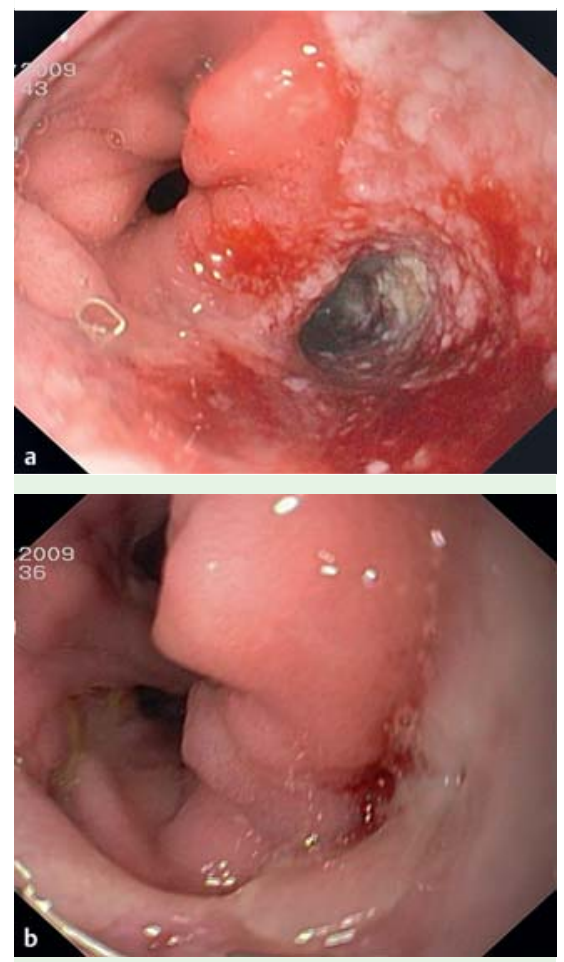

Fig. 4 View at completion of endoluminal vacuum therapy: a epithelialization of the abdominal fistula; and $\mathbf{b}$ the closed anastomotic leak.

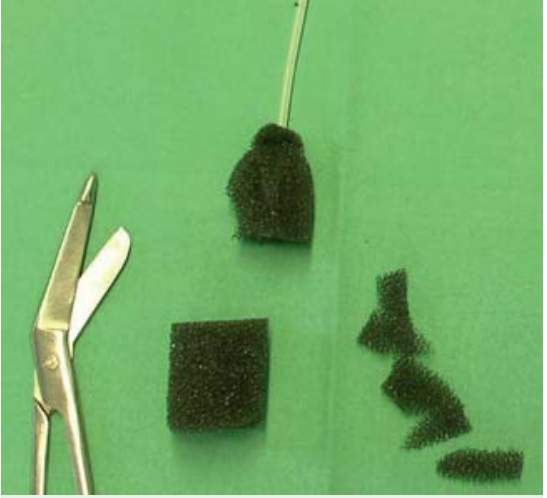

Fig. 2 Adjusting the sponge size.

The reported incidence of anastomotic leaks is between $5 \%$ and $25 \%$. Depending on the position and dimensions of the leaks, they are associated with a mortality of up to $60 \%$ [1]. So far endoluminal vacuum therapy has mainly been used for treatment of anastomotic insufficiencies of the rectum [2]. Its use in the esophagus was first reported in 2007 and in only three more cases since then [3-5].

Here we report a case of a 67-year-old man who developed an anastomotic insufficiency following gastrectomy. Postoperatively, the patient presented a severely septic clinical picture and therefore surgical revision was impossible. He was ventilated and given antibiotics. On endoscopic examination 7 days after gastrectomy, a $1-\mathrm{cm}$ leak covering $30 \%$ of the anastomotic circumference was noted, with an abdominal fistula. We started endoluminal vacuum therapy by endoscopic insertion of the Endo-SPONGE system (B. Braun Melsungen AG, Melsungen, Germany; Fig. 1) into the esophagus. The Endo-SPONGE is an open-pored polyurethane sponge. Before insertion, we adjusted its size according to the local topography of the esophagus ( Fig. 2). The sponge was placed via an overtube into the region of the anastomotic insufficiency at the distal end of the esophagus ( Fig. 3). The suction tube was extended with a nasogastric tube and secretions were continuously evacuated with a suction of $13.3 \mathrm{kPa}$. Following daily suction 
of $200-400 \mathrm{~mL}$ of secretions, the patient's condition improved remarkably within a few days. We carried out the procedure for a total of 18 days, changing the EndoSPONGE system every second or third day. The abdominal fistula underwent marked reduction and the anastomotic area epithelialized ( Fig. 4). The leak was no longer detectable on radiographs and the patient recovered completely. In summary, endoluminal vacuum therapy offers an alternative method for the treatment of complicated anastomotic insufficiency following esophageal or gastric surgery.

\section{Competing interests: None}

Endoscopy_UCTN_Code_TTT_1AO_2AI

\section{Wallstabe ${ }^{1}$, R. Plato ${ }^{2}$, A. Weimann ${ }^{2}$}

1 Department of Gastroenterology and Hepatology, Klinikum St. Georg, Leipzig, Germany

2 Department of General and Visceral Surgery, Klinikum St. Georg, Leipzig, Germany

\section{References}

1 Messmann H, Schmidbaur W, Jäckle J et al. Endoscopic and surgical management of leakage and mediastinitis after esophageal surgery. Best Pract Res Clin Gastroenterol 2004; 18: 809-827

2 Weidenhagen $R$, Grützner KU, Kopp $R$ et al. Role of vacuum therapy in the management of the septic abdomen. Zentralbl Chir 2006; 131: $115-119$

3 Wallstabe I, Weimann A. Eine neue endoskopische Technik im Management der Anastomoseninsuffizienz nach Ösophaguschirurgie. Z Gastroenterol 2007; 45: K14
4 Wedemeyer J, Schneider A, Manns MP et al. Endoscopic vacuum-assisted closure of upper intestinal anastomotic leaks. Gastrointest Endosc 2008; 67: 708 - 711

5 Loske G, Müller C. Vacuum therapy of an esophageal anastomotic leakage-a case report. Zentralbl Chir 2009; 134: 267-270

\section{Bibliography}

DOI $10.1055 / \mathrm{s}-0029-1244148$

Endoscopy 2010; 42: E165 -E166

(c) Georg Thieme Verlag KG Stuttgart · New York . ISSN 0013-726X

\section{Corresponding author}

\section{Ingo Wallstabe, MD}

Department of Gastroenterology and Hepatology Klinikum St. Georg

Delitzscher Str. 141

04129 Leipzig

Germany

Fax: +49-341-9092673

wallstabe@endoskopieren.de 